\title{
Does the fracture toughness of bulk metallic glasses scatter?
}

Wen Chen $^{\text {a }}$, Jittisa Ketkaew ${ }^{\text {a }}$, Ze Liu ${ }^{\text {a,b }}$, Rodrigo Miguel Ojeda Mota ${ }^{\text {a }}$, Kevin O’Brien ${ }^{\text {a }}$, Caio Sene da Silva ${ }^{\text {a }}$, Jan Schroers ${ }^{\text {a, }}{ }^{*}$

${ }^{a}$ Department of Mechanical Engineering \& Materials Science, Yale University, New Haven, CT, 06511, USA

${ }^{\mathrm{b}}$ Center for Research on Interface Structures and Phenomena (CRISP), Yale University

*Corresponding author. Tel.: +1 203432 4346; fax: +1 2034326775 .

E-mail address: jan.schroers@yale.edu (J. Schroers) 
Abstract: A method is introduced to determine notch toughness of bulk metallic glasses (BMGs). Through thermoplastic replication of $\mathrm{Si}$ molds, unprecedented control in fabricating BMG toughness samples can be achieved and influences such as cooling rate, thermal history, residual stress, sample geometry, and notch precision are drastically reduced. For the 20 $\mathrm{Zr}_{44} \mathrm{Ti}_{11} \mathrm{Cu}_{10} \mathrm{Ni}_{10} \mathrm{Be}_{25}$ BMG samples, we measured a notch toughness of $109 \pm 3 \mathrm{MPa} \sqrt{\mathrm{m}}$. Such a much smaller scatter than previously reported suggests reliable properties of BMGs when thermoplastically formed.

Keywords: fracture toughness; bulk metallic glass; thermoplastic forming Most engineering materials are not limited by their strength; but rather by their fracture toughness [1]. For the majority of structural applications, the selection criterion for materials is based on a combination of mechanical properties such as strength, elasticity, stiffness, and toughness [2]. Bulk metallic glasses (BMGs) are a class of structural materials which generally exhibit high strength and high elasticity, paired with unique processabilities [3-6]. Despite their similar atomic structure and in contrast to other classes of glasses, the fracture toughness of BMGs, $K_{c}$, varies dramatically. Close to ideally brittle behavior, e.g., $K_{c} \approx 2 \mathrm{MPa} \sqrt{\mathrm{m}}$ for a Mgbased BMG $[7,8]$, to remarkably tough, e.g., $K_{c} \approx 200 \mathrm{MPa} \sqrt{\mathrm{m}}$ for a Pd-based BMG has been reported [9]. It has been suggested that the origin of the widely ranging behavior within BMGs stems from a wide variation of their ratio of shear modulus $(G)$ to bulk modulus $(B)[10,11]$. A small $G$ promotes extension of a shear band and a high $B$ makes the transition from a shear band into a crack energetically more difficult [10]. Recently, more experimental evidence revealed limitations of the $G / B$ criterion [12]. This triggered the development of the critical fictive temperature concept to describe the wide range of fracture and embrittlement behavior among BMGs [13]. But even within a given BMG alloy, wide scatter in $K_{c}$ has also been reported. For 
example, the reported pre-crack toughness ranges from 16 to $74 \mathrm{MPa} \sqrt{\mathrm{m}}$ for $\mathrm{Zr}_{41.2} \mathrm{Ti}_{12.5} \mathrm{Cu}_{10} \mathrm{Ni}_{10} \mathrm{Be}_{22.5}$ BMG [14-19], while $K_{c}$ from 28 to $69 \mathrm{MPa} \sqrt{\mathrm{m}}$ for $\mathrm{Zr}_{52.5} \mathrm{Al}_{10} \mathrm{Ti}_{5} \mathrm{Cu}_{17.9} \mathrm{Ni}_{14.6} \mathrm{BMG}$ was reported [20]. Some work argued that observed scatter originates from processing conditions. Various authors suggested cooling rate during casting [21], residual stress [22], chemistry variation such as composition fluctuations and impurity inclusions $[15,23,24]$, sample geometry [25], and sharpness of notch/crack fabrication [26] as origins for the wide scatter. Others suggested that observed toughness scatter in BMGs has an intrinsic structural origin, and such scatter depends on the specific loading mode. For example, Tandaiya et al. found that the toughness scatter varies with different loading mode mixities [27], and Narayanan et al. recently reported a significantly larger scatter under mode-I than mode-II loading [28]. Clarification of the magnitude in variation of $K_{c}$ in BMGs is not only from a fundamental research point of uttermost importance to understand structure-property relationships in metallic glasses, but also mandatory for the commercial usage of BMGs as structural materials.

This long-standing issue in fracture toughness measurements of BMGs has been to a large extent attributed to the inability to precisely and repeatedly fabricate test samples under controlled conditions [29]. In this work, we propose a novel method where we mitigate previously suggested contributions to the scatter of $K_{c}$. Our approach is based on thermoplastic forming (TPF) of BMGs which we use to precisely replicate Si molds (Fig. 1) [30, 31]. In this work, we consider a representative, medium-tough and well studied $\mathrm{Zr}$-based $\mathrm{BMG}, \mathrm{Zr}_{44} \mathrm{Ti}_{11} \mathrm{Cu}_{10} \mathrm{Ni}_{10} \mathrm{Be}_{25}$, with onset glass transition temperature, $T_{g}=623 \mathrm{~K}$, and onset crystallization temperature $T_{x}=$ $744 \mathrm{~K}[14,22,32-35]$. Research grade $\mathrm{Zr}_{44} \mathrm{Ti}_{11} \mathrm{Cu}_{10} \mathrm{Ni}_{10} \mathrm{Be}_{2}$ BMG plates with dimensions 125 $\mathrm{mm} \times 100 \mathrm{~mm} \times 5 \mathrm{~mm}$ were supplied by Materion. Master ingots of $\mathrm{Zr}_{44} \mathrm{Ti}_{11} \mathrm{Cu}_{10} \mathrm{Ni}_{10} \mathrm{Be}_{25}$ were 
alloyed from a charge of commercial grade pure elemental constituents in an argon atmosphere. The ingot was subsequently melted by vacuum induction and cast into a $\mathrm{Cu}$ mold. The amorphous nature of the BMGs was confirmed by X-ray diffraction (XRD-6000 Shimadzu) and differential scanning calorimetry (Perkin Elmer Diamond DSC). Single edge notched tension (SENT) sample geometry is designed in general accordance with ASTM E399 with sample width, $W=8 \mathrm{~mm}$, length, $L=42 \mathrm{~mm}$ (gauge length $\mathrm{L}^{\prime}=35.2 \mathrm{~mm}$ ), and thickness, $t \approx 0.3 \mathrm{~mm}$. A notch with root radius $\rho=150 \pm 1 \mu \mathrm{m}$ was precisely introduced to a depth of $a / W=0.5$ (i.e., $a=$ $4 \mathrm{~mm}$ ) from the central edge of the sample, and a pair of two holes were designed in each end of the sample to facilitate alignment during uniaxial tension tests (Fig. 1). Si photolithography combined with deep reactive ion etching is employed to fabricate the molds with an etching depth of $\sim 0.35 \mathrm{~mm}$. $\mathrm{Zr}_{44} \mathrm{Ti}_{11} \mathrm{Cu}_{10} \mathrm{Ni}_{10} \mathrm{Be}_{25}$ BMGs were formed into Si molds by TPF molding at $700 K$ under a pressure of $20 \mathrm{MPa}$ for 100 seconds and subsequently water quenched to ensure a controlled and constant thermal history, and hence similar thermal residual stress. Fracture toughness tests were conducted on an Instron 5543 machine under a quasi-static displacementcontrolled mode (strain rate: $10^{-4} \mathrm{~s}^{-1}$ ). In order to correlate the Load-displacement curves with the notch propagation and plastic zone development, in-situ deformation images were recorded by a Qimaging Go-5 CCD camera. Through our approach, we prepared 20 SENT samples under identical processing conditions, and conducted fracture toughness test for each specimen.

A representative load - displacement curve associated with the corresponding plastic zone development is shown in Fig. 2. Fracture toughness in BMGs is generally believed to be a competition between shear banding and crack nucleation due to shear induced dilatation in relatively ductile BMGs or cavitation in brittle BMGs $[9,27,36]$. The capability of shear 
banding determines a characteristic material length scale, so called plastic process zone size, $R_{p}$, which herein represents the maximum spatial extension of shear bands ahead of an opening crack-tip prior to final instable failure [37]. Therefore, shear banding process constitutes the mechanism of plastic process zone development and it is terminated upon the intervention of final instable crack extension [9]. After elastic deformation (Fig. 2, A - B), shear bands start to initiate when the far field uniaxial tensile stress $\sigma$ reaches up to $\sim 200 \mathrm{MPa}$ (Fig. 2 stage B) and the SENT BMG specimen plastically yields locally around the notch. Thereafter, plastic zone further develops through proliferation of newly formed shear bands and propagation of existing shear bands (Fig. $2 \mathrm{C}-\mathrm{G}$ ). The shear banding process ends and ultimate fracture instability occurs once the extension of shear bands reaches a critical crack length (plastic zone size, $R_{p}$ ) at a fracture stress of $\sigma_{f}=338 \mathrm{MPa}$ (Fig. $2 \mathrm{H}$ ), where the final strain $\varepsilon \approx 2.2 \%$, which is slightly higher than the typical tensile strain of $\varepsilon \approx 2 \%$ for a monolithic BMG [37] due to the notch crack opening displacement and the plastic shear banding behavior ahead of the notch in the SENT geometry. The stress intensity factor $K$ for the present SENT geometry can be calculated through $K=\sigma \sqrt{\pi a} F\left(\frac{a}{W}\right)$, where $F\left(\frac{a}{W}\right)$ is a configuration correction factor [38]

$$
F\left(\frac{a}{W}\right)=\sqrt{\frac{2 W}{\pi a} \tan \frac{\pi a}{2 W}} \cdot \frac{0.752+2.02\left(\frac{a}{W}\right)+0.37\left(1-\sin \frac{\pi a}{2 W}\right)^{3}}{\cos \frac{\pi a}{2 W}}
$$

Hence, a notch fracture toughness $K_{Q} \approx 107 \mathrm{MPa} \sqrt{\mathrm{m}}$ for this representative case is measured. It is worth noting that Eq. (1) applies to a test sample with an ideal sharp crack (pre-crack) and the material exhibits linear elastic or small scale plastic yielding behavior under the plane strain condition. According to the recommendation of ASTM E399, for the determination of a planestrain $K_{I c}$, the specimen thickness $t$, the notch length $a$, and the length of the uncracked ligament (W-a) all need to satisfy the following condition: $a, t, W-a \geq 2.5\left(\frac{K_{c}}{\sigma_{y s}}\right)^{2}$, where $\sigma_{y s}$ is the yield 
strength of the BMG and $\sigma_{y s} \approx 1.9 \mathrm{GPa}$ [39]. Therefore, for observed notch toughness, geometric requirements are: $a, t, W-a \geq 8 \mathrm{~mm}$. This geometry, however, is difficult to prepare in uniform and high-quality even considering the robust glass forming ability, which is reflected in a critical casting dimension of $8 \sim 14 \mathrm{~mm}$ [40]. Such a plane-strain condition is even more challenging to establish in some poorer glass forming alloys such as $\mathrm{Pd}_{79} \mathrm{Ag}_{3.5} \mathrm{P}_{6} \mathrm{Si}_{9.5} \mathrm{Ge}_{2} \mathrm{BMG}\left(K_{Q} \approx 200 \mathrm{MPa}\right.$ $\sqrt{\mathrm{m}}$ ) that requires: $a, t, W-a>45 \mathrm{~mm}$, which is remarkably in excess of its critical casting dimension of only $6 \mathrm{~mm}$ [9]. The notch here is relatively blunt and the sample thickness is relatively thin, which may result in an error in approximating the absolute value of the toughness. Therefore, we call the toughness value measured here as notch toughness $\left(K_{Q}\right)$ approximated by Eq. (1). Since the focus of this work is to precisely determine the material's intrinsic toughness behavior, and especially its reproducibility by mitigating previously reported extrinsic contributions, which can be achieved most efficiently for thin samples, we use $K_{Q}$ instead of $K_{I c}$. We found that our measured $K_{Q}$ is comparable to the reported notch toughness of a similar $\mathrm{Zr}$ based $\mathrm{BMG}, \mathrm{Zr}_{41.2} \mathrm{Ti}_{13.8} \mathrm{Cu}_{12.5} \mathrm{Ni}_{10.0} \mathrm{Be}_{22.5}$, of $K_{Q} \approx 105 \mathrm{MPa} \sqrt{\mathrm{m}}$ with a similar notch radius although the specimens used therein were significantly thicker (4 $\mathrm{mm}$ and $7 \mathrm{~mm}$ plates) [14]. To quantify the effect of sample thickness, we also conducted a separate fracture toughness test on a $50 \mu \mathrm{m}$ thick sample prepared by TPF and Si photolithography. We measured a similar notch toughness of $K_{Q} \approx 110 \mathrm{MPa} \sqrt{\mathrm{m}}$. The similar results for $7 \mathrm{~mm}, 4 \mathrm{~mm}, 300 \mu \mathrm{m}$, and $50 \mu \mathrm{m}$ thick test samples indicate an only weak influence of test sample thickness on $K_{Q}$, smaller than typical for conventional crystalline metals [41]. The weak dependence of $K_{Q}$ on the BMGs' sample thickness in the considered range is however unclear and a more systematic study is required. 
The measured notch toughness $K_{Q}$ and the corresponding plastic zone size $R_{p}$ of all tested 20 specimens are summarized in Fig. 3. Overall, $K_{Q}$ ranges from 105 to $114 \mathrm{MPa} \sqrt{\mathrm{m}}$, with an average value of $\overline{K_{Q}}=109 \mathrm{MPa} \sqrt{\mathrm{m}}$, and a standard deviation of $\sigma\left(K_{Q}\right)=3 \mathrm{MPa} \sqrt{\mathrm{m}}$, while $R_{p}$ varies from 372 to $417 \mu \mathrm{m}$, with an average value of $\overline{R_{P}}=394 \mu \mathrm{m}$, and a standard deviation of $\sigma\left(R_{p}\right)=16 \mu \mathrm{m}$. The maximum extent of plane-strain plastic zone size can be calculated by $[15$, 42]

$$
\mathrm{R}_{\mathrm{P}}=\frac{1}{4 \pi}\left(\frac{\mathrm{K}_{\mathrm{Q}}}{\sigma_{\mathrm{ys}}}\right)^{2}\left[(1-2 v)^{2}+\frac{3}{2}\right] \approx 0.126\left(\frac{\mathrm{K}_{\mathrm{Q}}}{\sigma_{\mathrm{y}}}\right)^{2}
$$

where $v \approx 0.35$ [5] is Poisson's ratio. Consequently, $R_{p} \approx 416 \mu \mathrm{m}$ is calculated, which is interestingly close to the directly measured $\overline{R_{P}}=394 \mu \mathrm{m}$ although the test specimens herein are relatively thin. Observed scatter in $K_{Q}$ for $\mathrm{Zr}_{44} \mathrm{Ti}_{11} \mathrm{Cu}_{10} \mathrm{Ni}_{10} \mathrm{Be}_{25}$ BMG is comparable to the toughness scatter in conventional crystalline metals such as a AISI 4340 steel $\left(1200{ }^{\circ} \mathrm{C}\right.$ Austenitized and oil quenched) that exhibited $K_{I c} \approx 67 \sim 73 \mathrm{MPa} \sqrt{\mathrm{m}}$ [43]. Even under mode-I measurements, where higher scatter has been recently suggested than in mode-II for as-cast BMGs [28], our measured mode-I notch toughness scatter is similar to the scatter for a Zr-based BMG, where only 3 specimens were tested and the notch radius was 10-20 $\mu \mathrm{m}$ [44], but is significantly lower than previously reported for many as-cast BMGs [29]. For example, variations in fracture toughness for $\mathrm{Zr}_{41.2} \mathrm{Ti}_{13.8} \mathrm{Cu}_{12.5} \mathrm{Ni}_{10.0} \mathrm{Be}_{22.5} \mathrm{BMG}$ from 16 to $74 \mathrm{MPa} \sqrt{\mathrm{m}}$ have been reported by different research groups [14-19] and for $\mathrm{Zr}_{52.5} \mathrm{Al}_{10} \mathrm{Ti}_{5} \mathrm{Cu}_{17.9} \mathrm{Ni}_{14.6} \mathrm{BMG}$, $K_{Q} \approx 28 \sim 69 \mathrm{MPa} \sqrt{\mathrm{m}}$ was reported [20]; for $\mathrm{Cu}_{49} \mathrm{Hf}_{42} \mathrm{Al}_{9}$ BMG, $K_{Q} \approx 55 \sim 75 \mathrm{MPa} \sqrt{\mathrm{m}}$ was reported [45]. It was suggested that such a broad range of fracture toughness originates from varying and often uncontrolled processing conditions during BMG test sample preparation [29]. For instance, elimination of the residual stress within the surface layer of a $\mathrm{Zr}_{44} \mathrm{Ti}_{11} \mathrm{Cu}_{10} \mathrm{Ni}_{10} \mathrm{Be}_{25}$ 
BMG due to rapid casting can decrease the (pre-crack) fracture toughness from 51 to $34 \mathrm{MPa}$ $\sqrt{\mathrm{m}}$ [22]. Recently, $\mathrm{Zhu}$ and co-workers quenched the $\mathrm{Cu}_{49} \mathrm{Hf}_{42} \mathrm{Al}_{9} \mathrm{BMG}$ under various cooling rates, and the fracture toughness can be almost tripled from 26 to $79 \mathrm{MPa} \sqrt{\mathrm{m}}$, associated with an increase in $R_{p}$, with elevating cooling rate from $40 \mathrm{~K} / \mathrm{s}$ to $10^{3} \mathrm{~K} / \mathrm{s}$ [46].

We attribute the observed small scatter of $K_{Q}$ as the reflection of an intrinsic fracture behavior of BMGs which in the past has been overshadowed by extrinsic sample preparation methods. Introduced sample preparation method mitigates extrinsic contributions to fracture due to a variety of features. Firstly, through TPF-based processing, extrinsic casting flaws such as microvoids, defects or even compositional inhomogeneities in BMGs during rapid quenching can be drastically reduced due to the high mobility and forming pressure. In many cases, the apparent "brittle-like" behavior of BMGs originates from these extrinsic flaws [47]. Secondly, compared to conventional mechanical machining method such as electrical discharge machining (EDM) that often introduces rough and corrugated notch tips [48, 49], a remarkable precision of $\sim 1 \mu \mathrm{m}$ by Si photolithography can be achieved in fabricating the test samples, including the sharpness and smoothness of the notch. In addition, different from mechanical machining, the notch introduction by TPF does not introduce extra residual stresses in the vicinity of the notch. The generation of residual stresses by EDM, on the other hand, can even result in crystallization of BMGs in the vicinity of the cut surface [50], which might vary the macroscopic shear banding behavior and hence cause degradation and fluctuations in $K_{Q}$. Thirdly, the timescale for structural relaxation or viscosity relaxation of a BMG can be estimated through the Vogel-FulcherTamman relaxation to $\sim 0.1$ seconds for the studied BMG at the processing temperature of $700 \mathrm{~K}$ [22]. Thus, TPF molding for 100 seconds within the supercooled state allows the BMG to fully 
relax into the metastable equilibrium of the supercooled liquid which eliminates all initially different thermal histories during casting. It is worth noting that the processing time of 100 seconds is far shorter than the onset crystallization time of $\sim 600$ seconds [51], and hence the TPF-based fabrication exerts a negligible effect on the ductility or toughness of BMGs [52]. Lastly, by subsequent water quenching from the processing temperature of $700 \mathrm{~K}$, all specimens experience identical thermal history, cooling rate, and hence similar internal thermal residual stress.

In conclusion, we measured the notch toughness of a $\mathrm{Zr}_{44} \mathrm{Ti}_{11} \mathrm{Cu}_{10} \mathrm{Ni}_{10} \mathrm{Be}_{25} \mathrm{BMG}$ from 20 SENT samples, and the results demonstrate an average value of $\overline{K_{Q}}=109 \mathrm{MPa} \sqrt{\mathrm{m}}$ with a standard deviation of $\sigma\left(K_{Q}\right)=3 \mathrm{MPa} \sqrt{\mathrm{m}}$. This small scatter is suggested to reflect an intrinsic origin that has in the past been overshadowed by other extrinsic sample preparation effects. We reduce such extrinsic effects through a novel sample preparation method comprising TPF of BMGs and $\mathrm{Si}$ photolithography. This approach mitigates influences such as cooling rate, thermal history, residual stress, sample geometry, and notch precision. Furthermore, our findings suggest that BMGs' structure is homogeneous on the length scale relevant for fracture and reveal that when BMGs are thermoplastically formed, very reliable fracture behavior and mechanical performance can be achieved, which is a requirement for structural applications of BMGs.

This work was supported by the Department of Energy through the Office of Basic Energy Sciences (\#DE SC0004889). Experimental help from Michael Kanik, and William Samela are gratefully acknowledged. Caio Sene da Silva would like to thank Brazilian Scientific Mobility Program for supporting the oversea visit to Yale University. 


\section{References:}

[1] M.E. Launey, R.O. Ritchie, Adv. Mater. 21 (2009) 2103.

[2] M.F. Ashby, D. Cebon, J. Phys. IV. 3 (1993) C7-1.

[3] G. Kumar, H.X. Tang, J. Schroers, Nature 457 (2009) 868.

[4] J. Schroers, Adv. Mater. 22 (2010) 1566.

[5] S.F. Guo, J.L. Qiu, P. Yu, S.H. Xie, W. Chen, Appl. Phys. Lett. 105 (2014) 161901

[6] C.A. Schuh, T.C. Hufnagel, U. Ramamurty, Acta Mater. 55 (2007) 4067.

[7] X.K. Xi, D.Q. Zhao, M.X. Pan, W.H. Wang, Y. Wu, J.J. Lewandowski, Phys. Rev. Lett. 94 (2005) 125510.

[8] G. Wang, D. Q. Zhao, H.Y. Bai, M. X. Pan, A.L. Xia, B. S. Han, X. K. Xi, Y. Wu, W. H. Wang, Phys. Rev. Lett. 98 (2007) 235501.

[9] M.D. Demetriou, M.E. Launey, G. Garrett, J.P. Schramm, D.C. Hofmann, W.L. Johnson, R.O. Ritchie, Nat. Mater. 10 (2011) 123.

[10] J. Schroers, W.L. Johnson, Phys. Rev. Lett. 93 (2004) 255506.

[11] J. Lewandowski, W. Wang, A. Greer, Phil. Mag. Lett. 85 (2005) 77.

[12] G. Kumar, S. Prades-Rodel, A. Blatter, J. Schroers, Scripta Mater. 65 (2011) 585.

[13] G. Kumar, P. Neibecker, Y.H. Liu, J. Schroers, Nat. Comm. 4 (2013) 1536.

[14] P. Lowhaphandu, J.J. Lewandowski, Scripta Mater. 38 (1998) 1811.

[15] R.D. Conner, A.J. Rosakis, W.L. Johnson, D.M. Owen, Scripta Mater. 37 (1997) 1373.

[16] C. J. Gilbert, V. Schroeder, R.O. Ritchie, Metall. Mater. Trans. A 30 (1999) 1739.

[17] D. Suh, R.H. Dauskardt, Ann. Chim. Sci. Mat. 27 (2002) 25.

[18] D. Suh, R.H. Dauskardt, J. Non-cryst. Solids 317 (2003) 181. 
[19] C.P. Kim, J.-Y. Suh, A. Wiest, M.L. Lind, R.D. Conner, W.L. Johnson, Scripta Mater. 60 (2009) 80.

[20] J. Schneibel, J. Horton, P. Munroe, Metall. Mater. Trans. A 32 (2001) 2819.

[21] X. Gu, S.J. Poon, G.J. Shiflet, J. Lewandowski, Scripta Mater. 60 (2009) 1027.

[22] M. Launey, R. Busch, J. Kruzic, Acta Mater. 56 (2008) 500.

[23] S.V. Madge, D.V. Louzguine-Luzgin, J.J. Lewandowski, A.L. Greer, Acta Mater. 60 (2012) 4800.

[24] A. Shamimi Nouri, X. Gu, S. Poon, G. Shiflet, J. Lewandowski, Phil. Mag. Lett. 88 (2008) 853.

[25] K.M. Flores, R.H. Dauskardt, Scripta Mater. 41 (1999) 937.

[26] D.L. Henann, L. Anand, Acta Mater. 57 (2009) 6057.

[27] P. Tandaiya, U. Ramamurty, R. Narasimhan, J. Mech. Phys. Sol. 57 (2009) 1880.

[28]R.L. Narayan et al., Scripta Mater. (2015) http://dx.doi.org/10.1016/j.scriptamat.2015.02.017

[29] J. Xu, U. Ramamurty, E. Ma, JOM 62 (2010) 10.

[30] W. Chen, Z. Liu, H.M. Robinson, J. Schroers, Acta Mater. 73 (2014) 259.

[31] B. Sarac, J. Schroers, Nat. Comm. 4 (2013) 1.

[32] J.J. Lewandowski, Mater. Trans. 42 (2001) 633.

[33] P. Lowhaphandu, L. Ludrosky, S. Montgomery, J.J. Lewandowski, Intermetallics, 8 (2000) 487.

[34] M. Launey, R. Busch, J. Kruzic, Scripta Mater. 54 (2006) 483.

[35] W. Chen, Z. Liu, J. Schroers, Acta Mater. 62 (2014) 49.

[36] E. Bouchaud, D. Boivin, J.-L. Pouchou, D. Bonamy, B. Poon, G. Ravichandran, Europhys. Lett. 83 (2008) 66006. 
[37] D.C. Hofmann, J.-Y. Suh, A. Wiest, G. Duan, M.-L. Lind, M.D. Demetriou, W.L. Johnson, Nature 451 (2008) 1085.

[38] H. Tada, P. Paris, G. Irwin, The Analysis of Cracks Handbook, New York: ASME Press, 2000.

[39] H.A. Bruck, T. Christman, A.J. Rosakis, W.L. Johnson, Scripta Metall. Mater. 30 (1994) 429.

[40] A. Peker, W.L. Johnson, Appl. Phys. Lett. 63 (1993) 2342.

[41] T.L. Anderson, Fracture mechanics: fundamentals and applications, CRC press, 2005.

[42] F. McClintock, G. Irwin, Plasticity aspects of fracture mechanics: Fracture toughness testing and its applications (ASTM STP) 381 (1965) 84.

[43] R.O. Ritchie, B. Francis, W.L. Server, Metall. Trans. A, 7 (1976) 831.

[44] B. Gludovatz, S.E. Naleway, R.O. Ritchie, J.J. Kruzic, Acta Mater. 70 (2014) 198.

[45] P. Jia, Z.D. Zhu, E. Ma, J. Xu, Scripta Mater. 61 (2009) 137.

[46] Z.-D. Zhu, E. Ma, J. Xu, Intermetallics 46 (2014) 164.

[47] S.-G. Wang, M.-Y. Sun, Z.-Q. Song, J. Xu, Intermetallics 29 (2012) 123.

[48] P. Tandaiya, R. Narasimhan, U. Ramamurty, Acta Mater. 61 (2013) 1558.

[49] V. Keryvin, Y. Nadot, Y. Yokoyama, Scripta Mater. 57 (2007) 145.

[50] S.-F. Hsieh, S.-L. Chen, M.-H. Lin, S.-F. Ou, W.-T. Lin, M.-S. Huang, J. Mater. Res. 28 (2013) 3177.

[51] T. Waniuk, J. Schroers, W.L. Johnson, Phys. Rev. B 67 (2003) 184203.

[52] G. Kumar, D. Rector, R. Conner, J. Schroers, Acta Mater. 57 (2009) 3572. 


\section{Figure Captions}

Fig. 1 Schematics of the fabrication method of the single edge notched tension (SENT) BMG samples. (a) - (d) Si lithography and deep reactive ion etching are used to fabricate SENT Si molds with an etching depth of $\sim 350 \mu \mathrm{m}$. (e) - (g) Thermoplastic based molding is employed to replicate the Si molds in the BMG. The extra BMG is removed through a planarization step and the $\mathrm{Si}$ molds are subsequently etched in a $20 \% \mathrm{KOH}$ solution. The state-of-the-art $\mathrm{Si}$ photolithography technology offers a remarkable smoothness and precision on the notch fabrication.

Fig. 2 A representative load - displacement curve which is correlated with the sequential plastic process zone development.

Fig. 3 Measured notch toughness $K_{Q}$ (a) and plastic zone size $R_{p}$ (b) of all tested 20 $\mathrm{Zr}_{44} \mathrm{Ti}_{11} \mathrm{Cu}_{10} \mathrm{Ni}_{10} \mathrm{Be}_{25} \mathrm{BMG}$ specimens. An average notch toughness of $\overline{K_{Q}}=109 \mathrm{MPa} \sqrt{\mathrm{m}}$ with a standard deviation of $\sigma\left(K_{Q}\right)=3 \mathrm{MPa} \sqrt{\mathrm{m}}$ and an average plastic zone size of $\overline{R_{P}}=394 \mu \mathrm{m}$, with a standard deviation of $\sigma\left(R_{p}\right)=16 \mu \mathrm{m}$ is measured. 


\section{Figures}

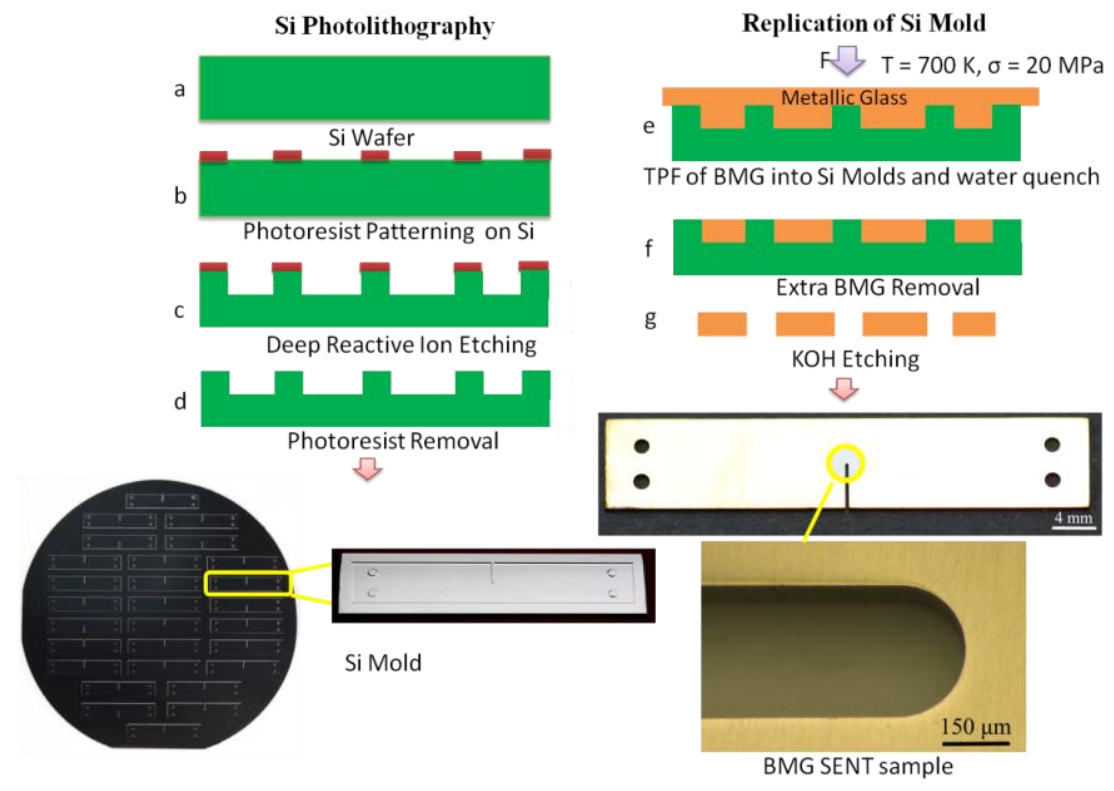

Fig. 1 Chen $W$ et al. 

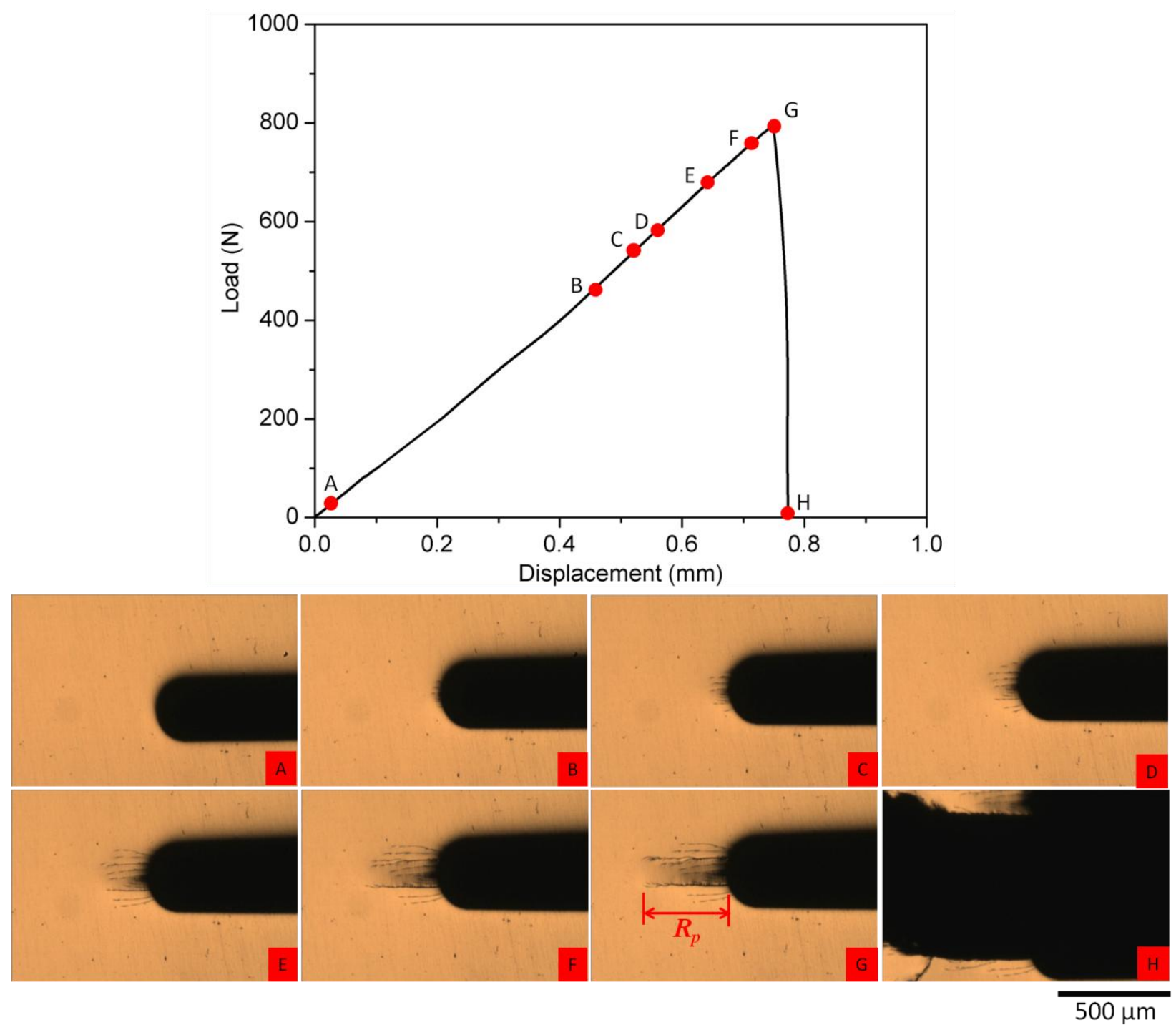

Fig. 2 Chen $W$ et al. 

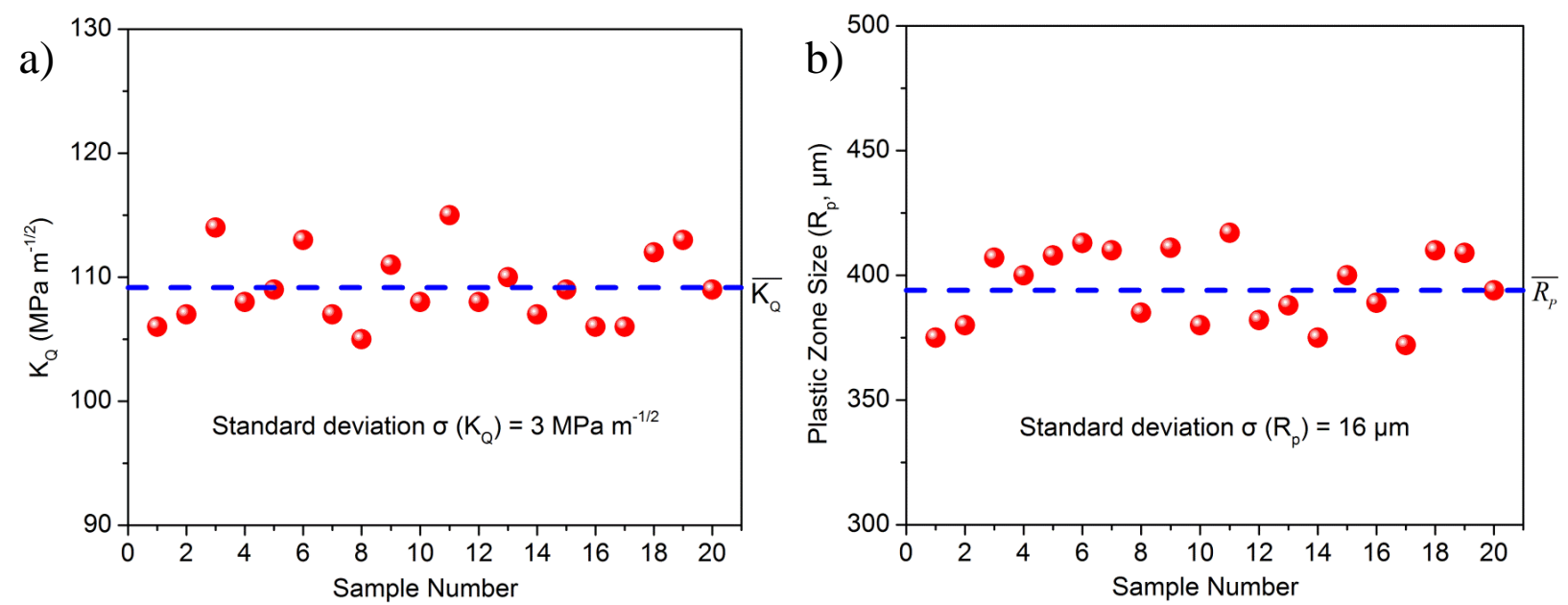

Fig. 3 Chen $W$ et al. 